'Departamento de Pesquisa

Agropecuária, Diretoria de Pesquisa e Desenvolvimento, Instituto

Agronômico de Pernambuco (IPA),

Av. General San Marin, 1371

CEP 50761-000, Recife, PE, Brasil

${ }^{2}$ Laboratório Fungos de Solo,

Programa de Pós-graduação em

Fitopatologia, Universidade Federal

Rural de Pernambuco (UFRPE), Rua

Dom Manoel de Medeiros, s/n, Dois

irmãos, CEP 52171-900, Recife, PE,

Brasil

${ }^{3}$ Escola Lauro Ribeiro, Granja

Bretanhas, CEP 96300-000, Jaguarão,

RS, Brasil

${ }^{4}$ Universidade Federal do Piauí (UFPI),

Campus Professora Cinobelina Elvas,

BR 135, Km 3, Planalto Horizonte,

CEP 64900-000, Bom Jesus, PI, Brasil

*autor correspondente

\luiz.gonzaga@ipa.br

\section{Nova doença ameaça coqueirais brasileiros}

\author{
A new disease threats brazilian coconut palm plantations
}

Luiz Gonzaga Biones Ferraz ${ }^{*}$, Tereza Cristina de Assis ${ }^{1}$, Iwanne Lima Coelho²,

Michele Freitas Santiago ${ }^{3}$, Alice Maria Gonçalves Santos ${ }^{4}$
RESUMO: A nucicultura brasileira oferece cerca de 300 mil empregos, com faturamento anual superior a um bilhão de reais, porém está ameaçada pela doença 'atrofia letal da coroa do coqueiro' (ALCC). Há registro de coqueiros sintomáticos em sete Estados, inclusive em grandes plantações com coqueiros híbridos. Os sintomas são diferentes do 'amarelecimento letal do coqueiro', porém alguns deles se assemelham aos da 'porroca', que está devastando coqueirais no Caribe. Há resultados que sinalizam indiferença dela frente à genética do coqueiro e ao ambiente. Tem sido identificado Fusarium sp. em isolados de tecidos de coqueiro e há informação da presença de nanovírus. A etiologia da ALCC continua indefinida. Objetiva-se registrar o seguinte: 1) Propagação da ALCC em Pernambuco; 2) Ocorrência dela em outros Estados; 3) Sintomas para aprimoramento de escala diagramática da severidade da doença; 4) Resultados parciais; e 5) Necessidade de parceria para elaboração de projeto multidisciplinar e institucional na busca por alternativas sustentáveis de convivência com a ALCC.

PALAVRAS-CHAVE: Cocos nucifera, coqueiro, ALCC, porroca, Fusarium, nanovírus.
ABSTRACT: A new disease called 'lethal coconut palm crown atrophy' (ALCC - in Portuguese) threats the coconut palm exploration in Brazil. There is register of symptomatic plants in seven States and it is present in three of the largest plantations where most of them are hybrid coconut trees. Its symptoms are different of the 'lethal yellowing', but some of them show similarity with 'porroca'signs. The results here presented show its independence to genetic and environmental factors. Fusarium sp. has been identified in several isolated and there is information on the presence of nano-virus, but ALCC etiology remains undefined. The objective of this paper is to record the following: 1) Propagation of ALCC in Pernambuco; 2) Its occurrence in other States; 3) Symptoms for diagrammatic scale of severity; 4) Partial results; and 5) Necessity for partnership for develop multidisciplinary project for sustainable alternatives of coexistence with ALCC.

KEYWORDS: Cocos nucifera, coconut tree, ALCC, porroca, Fusarium, nano-virus.

\section{Introdução}

O coqueiro é explorado em cerca de 90 países, em área de doze milhões de hectares, beneficiando mais de 80 milhões de pessoas. No Brasil, são 250 mil hectares, para produção anual de dois bilhões de frutos e faturamento superior a um bilhão de reais (INSTITUTO BRASILEIRO DE GEOGRAFIA E ESTATÍSTICA, 2015).

A estatística de alguns segmentos da cadeia produtiva de coco não é de fácil apuração, o que dificulta precisar o desempenho socioeconômico dela no Brasil. Todavia para aquilatar sua relevância basta considerar o apurado anual, a previsão de 300 mil empregos gerados e o fato de a matéria prima advir, predominantemente, de pequenas propriedades.

Atualmente, a doença que mais preocupa a comunidade nucícola internacional é o 'amarelecimento letal do coqueiro' 
ou 'lethal yellowing'. Ela tem destruído coqueirais mundo a fora (HARRISON; ELLIOTT, 2008; BOURDEIX et al., 2016). O governo brasileiro tem envidado esforços para evitar a entrada e a disseminação dela no País.

No Brasil, a enfermidade conhecida por 'resinose' foi incorporada ao sistema biológico de coqueiro e tem provocado morte de plantas em alguns Estados da federação (FERREIRA et al., 1998), inclusive em Pernambuco (FERRAZ et al., 2012a). Recentemente, os coqueirais brasileiros receberam mais um hóspede indesejável: 'ácaro vermelho das palmeiras'. Em outros países, ele chega a reduzir a produção de coco em até 70\% (DINIZ, 2009).

Têm sido localizadas em coqueirais brasileiros plantas com sintomas que apontam para uma nova enfermidade. Ela atrofia a coroa e causa morte da planta (FERRAZ et al., 2012b), o que levaram esses autores a denominarem-na de 'atrofia letal da coroa do coqueiro' $=$ ALCC.

Os sintomas dela não se assemelham aos de nenhuma doença dos diferentes grupos nos quais se enquadra o 'amarelecimento letal', o que gera certa tranquilidade. Contudo há similaridade entre algumas características dela e da enfermidade conhecida por 'porroca', que está devastando coqueirais no Caribe (UNIVERSITY OF CALIFORNIA, 2019). Além disso, há o agravante de a ALCC já estar presente em sete Estados brasileiros.

Em Pernambuco, a propagação da doença e a derrubada de milhares de coqueiros têm causado preocupação. Na Bahia, há coqueiral que zerou a produção anual de quatro milhões de cocos. Plantas com sinais da ALCC foram localizadas, também, nos seguintes Estados: Amazonas, Sergipe, Roraima, Paraíba e Pará. Há um agravante associado à ocorrência dessa enfermidade nos dois últimos Estados: ela já se encontra em grande coqueiral na Paraíba e se aproxima de dois outros do Pará, os quais, juntos, somam cerca de nove mil hectares.

Em $65 \%$ de 130 isolados de amostras de folhas de coqueiro com sintomas da ALCC, oriundas de Pernambuco e da Paraíba, cujas análises foram realizadas em laboratório do IPA, foi identificado Fusarium sp. Esse fungo também foi isolado em tecidos de cocos jovens oriundos dos municípios de Bonito e Ipojuca (PE). Todavia, até o momento, não foi comprovada patogenicidade dele para coqueiro. Há informação extraoficial da presença de nanovírus em material de ALCC oriundo do Pará.
Não obstante, considera-se que a ALCC poderá se constituir grave problema para a cadeia produtiva do coco no país. $\mathrm{O}$ título de um documento endereçado ao Ministro da Agricultura evidencia essa gravidade: Coqueiral: dossiê, vida e agonia (SILVA, 2016).

Com esta publicação, objetiva-se registrar o seguinte: 1) Propagação da ALCC em Pernambuco; 2) Ocorrência dela em outros Estados da Federação; 3) Morte de plantas e redução em produção; 4) Sintomas para auxiliar aprimoramento de escala diagramática; 5) Resultados parciais obtidos; e 6) Necessidade de parceria para elaboração de projeto multidisciplinar na busca por alternativas sustentáveis de convivência com a ALCC.

\section{Ocorrência da ALCC no Brasil}

Aqui constam detalhes adicionais aos do primeiro registro da ALCC (FERRAZ et al., 2012b) e ilustrações e informes sobre a ocorrência dela em mais seis Estados da federação.

\section{ALCC no Estado de Pernambuco}

Há registro da ALCC nos seguintes municípios: Abreu e Lima, Bom Jardim, Bonito, Carpina, Chã de Alegria, Feira Nova, Glória do Goitá, Goiana, Gravatá, Igarassu, Itambé, Itaquitinga, Lagoa de Itenga, Limoeiro, Machados, Macaparana, Moreno, Nazaré da Mata, Paudalho, Paulista, Recife, São Lourenço da Mata, Surubim, Tamandaré, Timbaúba, Tracunhaém, Vicência e Vitória de Santo Antão. Esses municípios estão em cinco das doze Regiões de Desenvolvimento (RD), com maior incidência na RD Mata Norte (Figura 1).

Até o momento, a ALCC está presente em cinco das sete RD's onde o coqueiro é explorado economicamente, significando $71,43 \%$ da área produtora de coco no Estado.

Confrontando os dados de hoje aos iniciais (FERRAZ et al., 2012b), a disseminação da doença nas RD's Mata Norte e Metropolitana foi relativamente rápida. Na Mata Sul ela se mantém quase que inalterada. Em Bom Jardim, Agreste do Estado, vizinho à RD Mata Norte, a produção anual de um coqueiral caiu de um milhão para cerca de 500 mil frutos. A seguir, exemplos de danos (Figura 2) provocados pela ALCC em coqueirais de diferentes municípios de Pernambuco, indicando o que a ALCC poderá impor à exploração do coqueiro no Brasil.

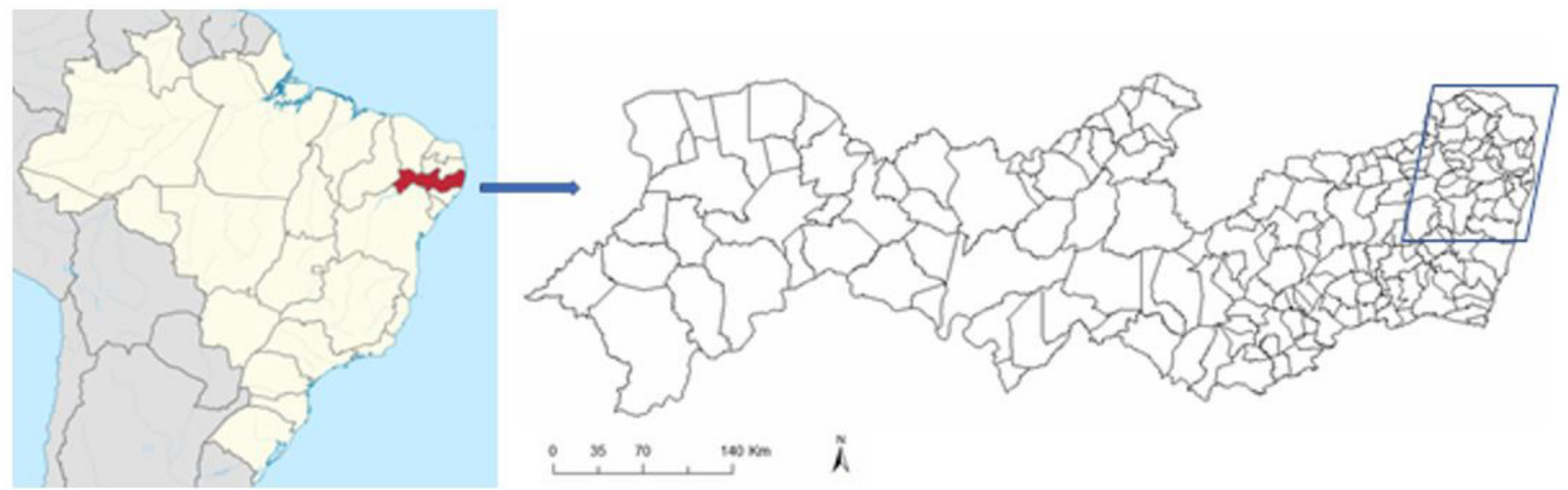

Figura 1. Mapa do Brasil, com destaque para o Estado de Pernambuco e para a RD Mata Norte. 

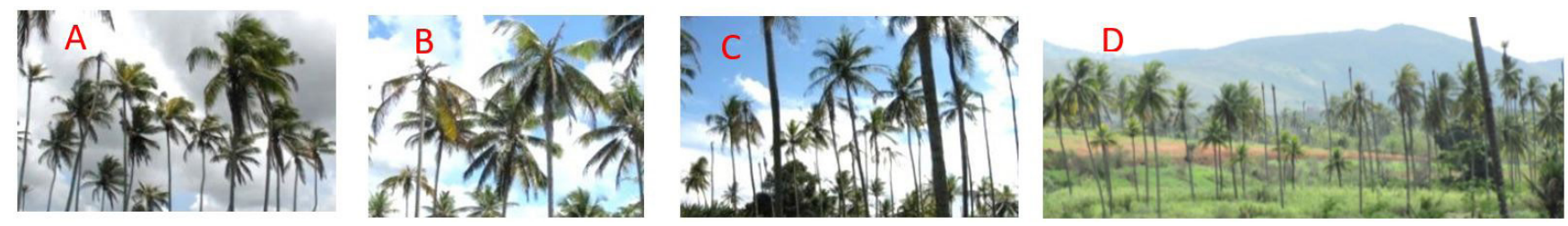

Figura 2. Sintomas da ALCC sobre coqueiros nos municípios de Goiana (A), Igarassu (B), Glória do Goitá (C) e Pombos (D), no Estado de Pernambuco. Fotos: Luiz Gonzaga Biones Ferraz.

Ao fundo da última imagem, tem-se a formação rochosa Planalto da Borborema. Ela divide os municípios de Vitória e de Pombos, ambos na RD Mata Sul, onde foram localizados coqueiros com ALCC apenas na porção que fica ao Norte dessa formação. Em Bonito, RD Agreste Central, somente há ALCC em coqueiral situado entre duas ramificações do Planalto.

\section{ALCC em outros Estados}

Foram localizadas plantas com sinais característicos da ALCC (Figura 3) nos seguintes Estados: Amazonas, Pará, Paraíba, Bahia, Sergipe e Roraima.

De acordo com esses registros, a ALCC está presente em apenas sete dos 25 Estados produtores de coco, o que significam $28,0 \%$ do total. Todavia, considerando que ainda não se tem levantamento em nível nacional, esse porcentual poderá chegar ao máximo.

\section{Ocorrência da ALCC Fora do Brasil}

Coqueiros apresentando sintomas similares aos da ALCC (Figura 4), têm sido localizados na Guiana e no Caribe.
Referindo-se à enfermidade retro ilustrada (Figura 4B), Villareal (2019) informa que a situação na região do Caribe é crítica, devido à letalidade da doença, que é conhecida ali como 'porroca' (folhas curtas). Além disso, o potencial dessa enfermidade é devastador e ela está se propagando rapidamente da Colômbia em direção ao Panamá (UNIVERSITY OF CALIFORNIA, 2019).

\section{Registros e Ações Acerca da 'ALCC' em Pernambuco}

Diversos profissionais da área estiveram em visita a coqueirais com ALCC, no Estado de Pernambuco, como por exemplo: Rildo Sartori (saudosa memória), Vanildo Cavalcanti, Tereza Cristina de Assis, Francisco Lopes, Regina Ceres e Rodrigo Leandro (do IPA), Gilvan Pio, Genira Andrade, Clístenes Araújo e Iwanne Coelho (UFRPE), Joana Ferreira, Viviane Talamini, Adenir Teodoro e Leandro Eugenio (da Embrapa Tabuleiros Costeiros), Alessandra Boari (da Embrapa Amazônia Oriental), Paulo Lins (da Sococo) e Michel Dollet (do Cirad - França).
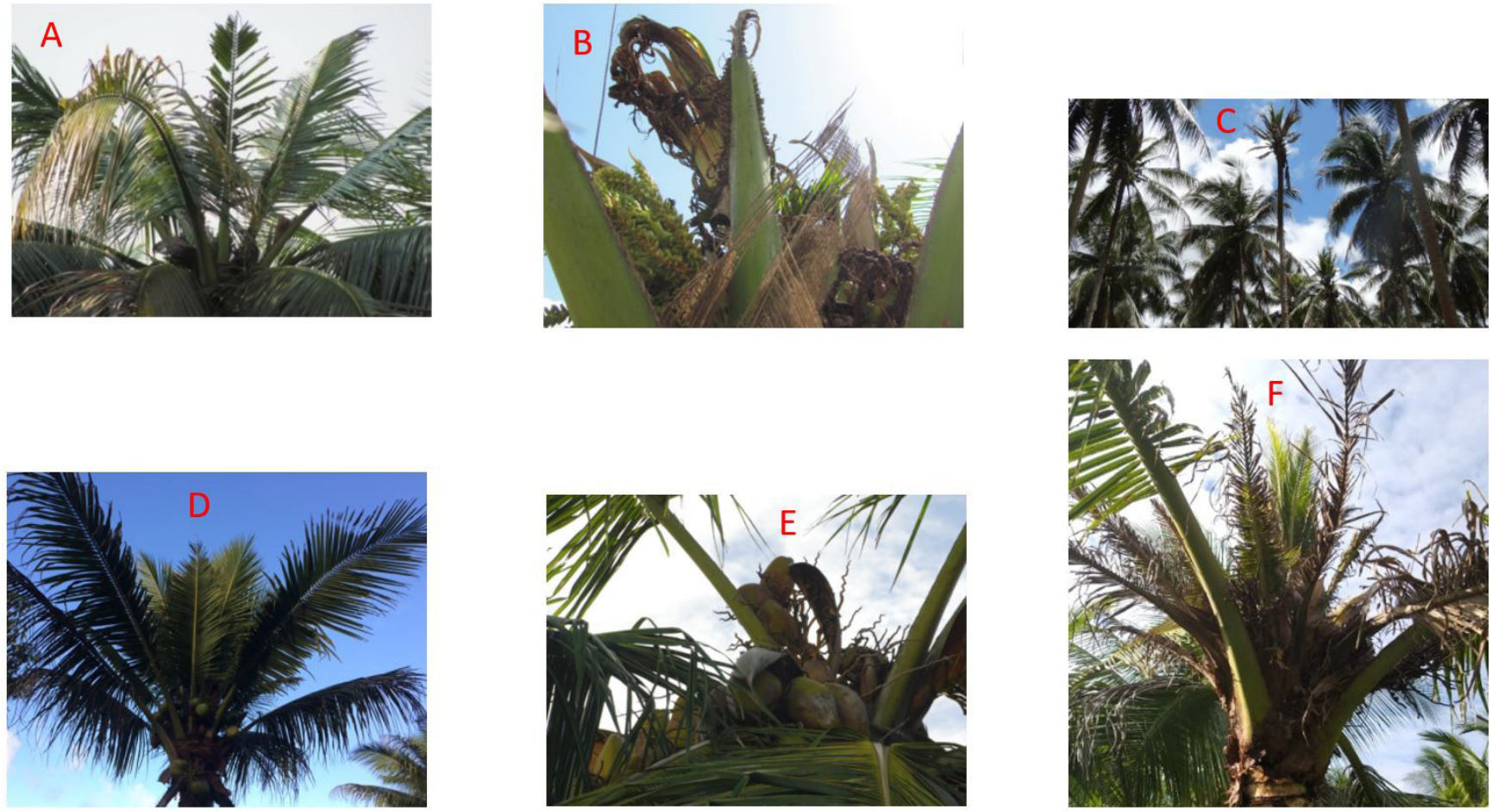

Figura 3. Coqueiros com sintomas da ALCC em Manaus (A), Santa Izabel do Pará (B), Lucena (C), Una (D), Aracaju (E) e Boa Vista (F). Fotos: Luiz Gonzaga Biones Ferraz, Fhelipe Viana Quaglia (D) e Luiz Cláudio Santos Estrela (F). 


\section{Particularidades da ALCC}

- Independência dos seguintes fatores: genética (anões, híbridos, gigantes); idade (um ano de campo a adulto); manejo (irrigado a extrativismo); solo (arenoso a argiloso); altitude (nível do mar a 450 metros); extensão de área (pomar a grandes plantações); e sistema de plantio (solteiro e consorciado);

- Longevidade de plantas com sinais da ALCC: variável;

- Propagação para plantas vizinhas: velocidade variável. Há coqueiros que se mantêm sadios mesmo estando ao lado de coqueiros com ALCC (Figura 5);

- Recuperação (Figura 6): sucesso e insucesso sob ação de sulfato de zinco; recuperação parcial de coqueiral sob ação de diversos agroquímicos; e paralisação da recuperação.

\section{Sintomatologia da ALCC}

Como já se viu, ocorre redução da coroa a partir dos tecidos da região de crescimento. Seguem mais sintomas sobre flecha, folha, inflorescência e estipe do coqueiro (Figura 7).

Como se vê nessa imagem, a redução dos tecidos foliares é bastante acentuada. A folha, que pode medir até cinco metros de comprimento, fica restrita a pouco mais de meio metro.

Têm sido observadas variações na expressão sintomatológica de plantas com ALCC (Figura 8). É possível que elas estejam associadas a mais de uma enfermidade.

O isolamento de Fusarium sp. de coqueiro com ALCC em plantio consorciado com banana Maçã, onde houve alta incidência de mal-do-Panamá, suscitou dúvida sobre a parte interior do estipe. Aparentemente, não houve danos aos vasos condutores (Figura 9).
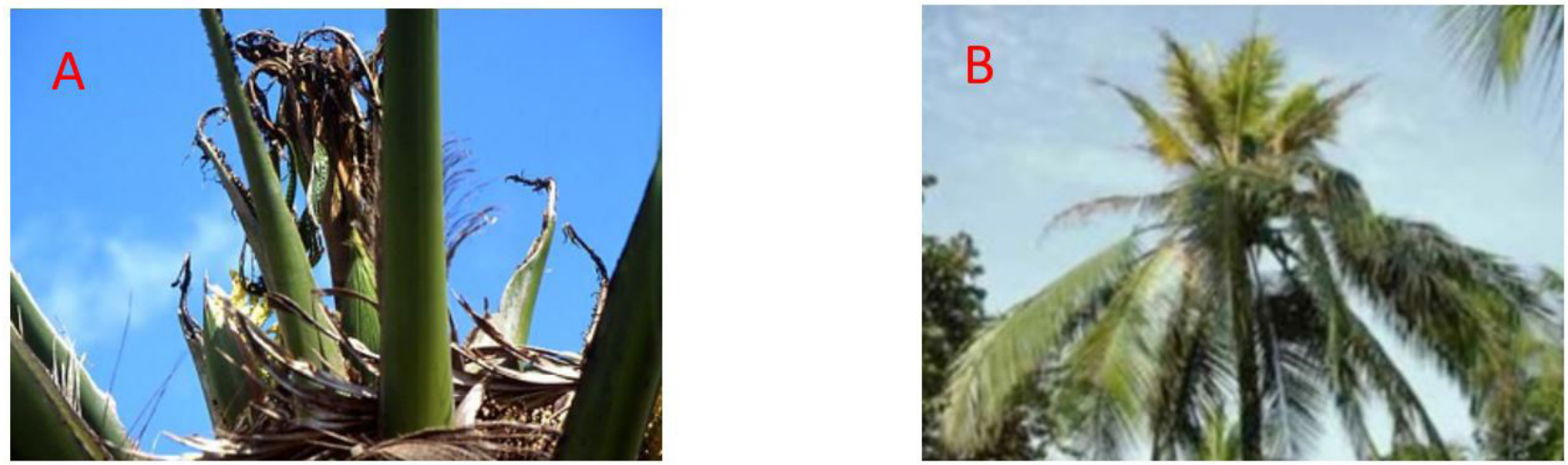

Figura 4. Coqueiros com sintomas semelhantes aos da ALCC, na Guiana (A) e na região do Caribe (B). Fotos: Michel Dollet e http://parker.eeb.ucsc.edu/ research/evolutionary-ecology-of-plant-disease/, respectivamente.
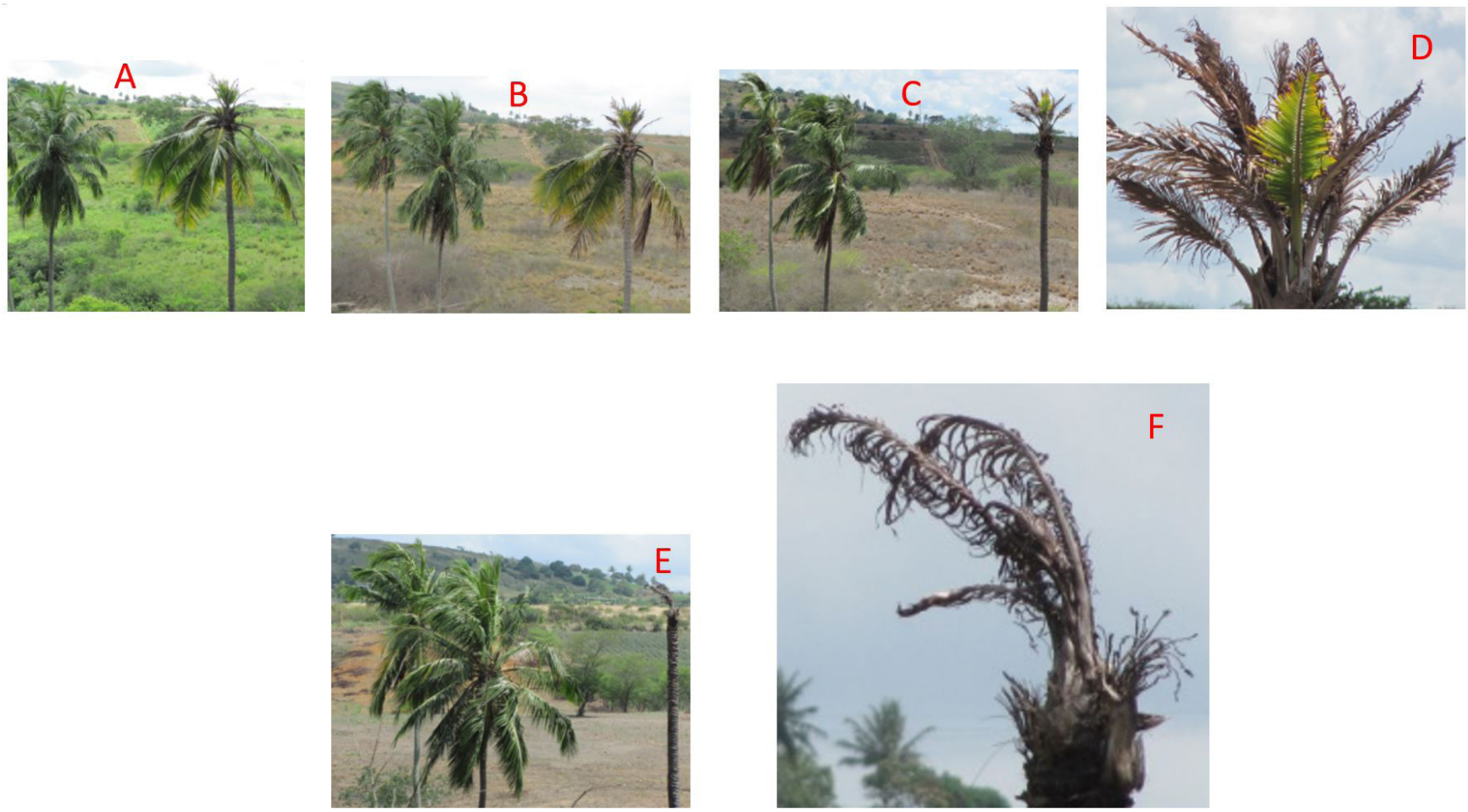

Figura 5. Coqueiros sadios ao lado de coqueiro com ALCC e evolução da doença: julho/2012 (A); outubro/2012 (B); abril/2013 (C e D); e outubro/2013 (E e F). Serra das Russas, Pombos, Pernambuco. Brasil. Fotos: Luiz Gonzaga Biones Ferraz. 

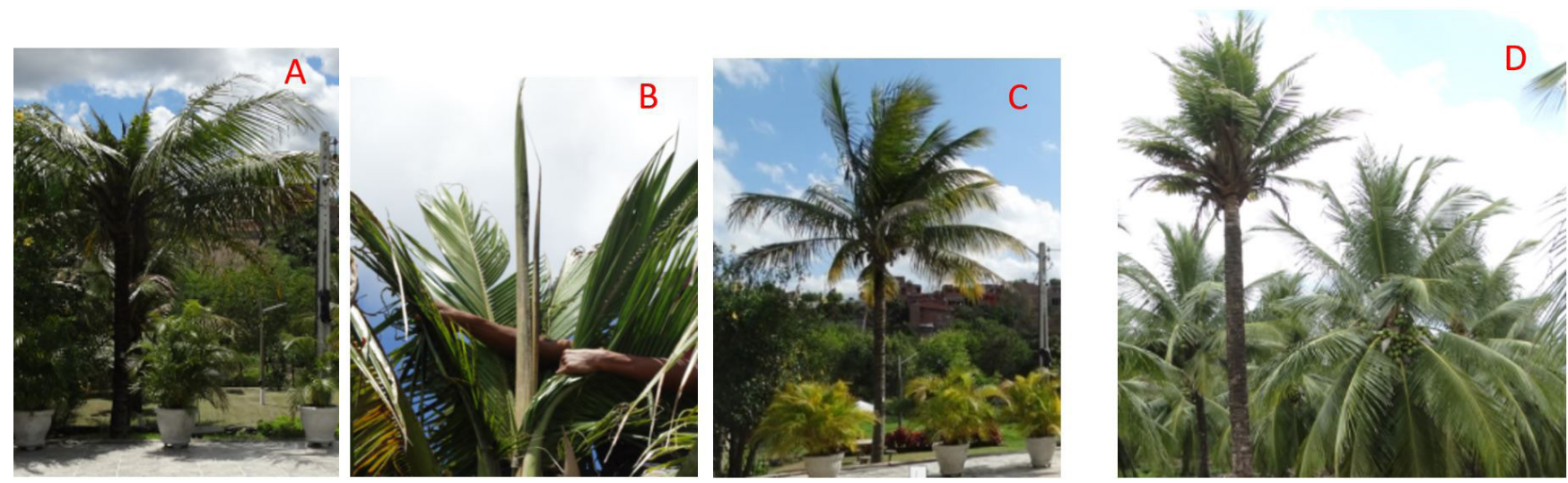

Figura 6. Coqueiro com ALCC em pomar residencial e sinais de recuperação dele (A, B e C), em Gravatá, recuperação parcial em plantação comercial (D), em Bom Jardim, ambos em Pernambuco, Brasil. Fotos: Luiz Gonzaga Biones Ferraz.
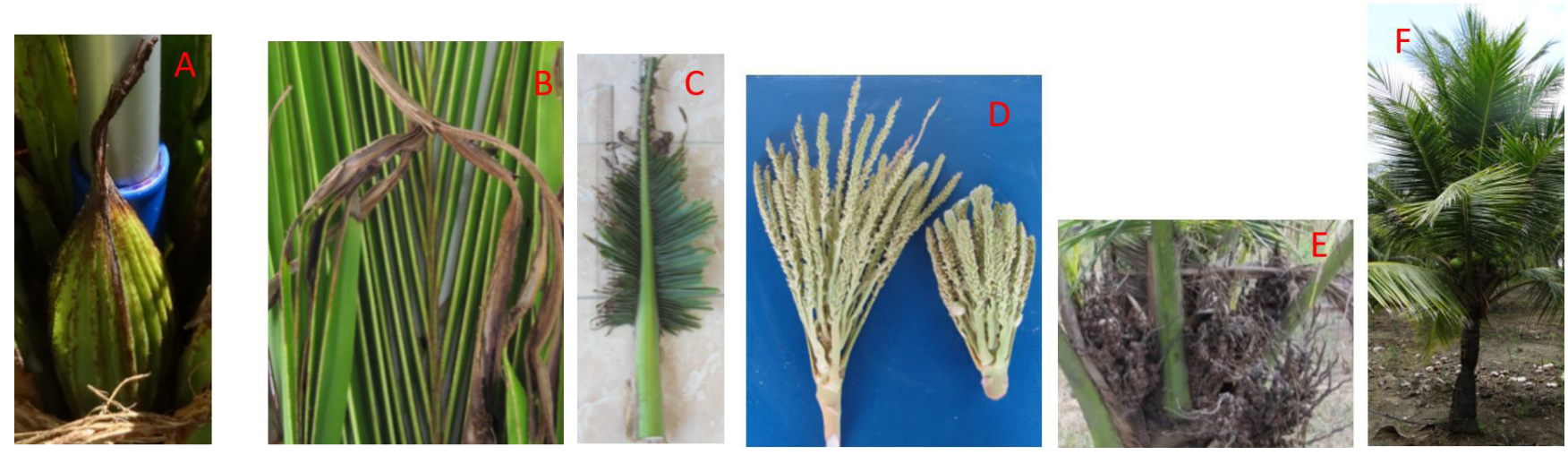

Figura 7. Sintomas da ALCC sobre: flecha (A), folha (B e C), inflorescência (D e E) e estipe do coqueiro (F). Fotos: Luiz Gonzaga Biones Ferraz.
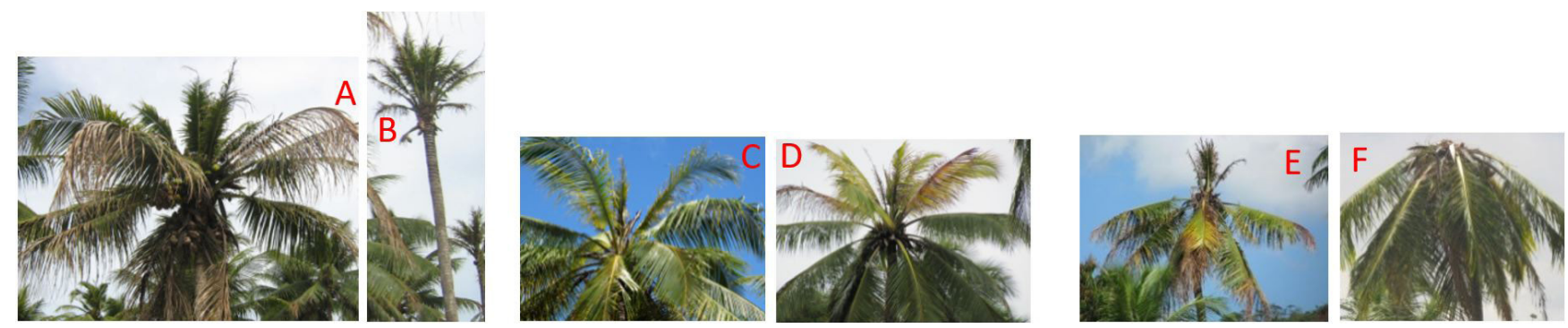

Figura 8. Variação sintomatológica da ALCC: retenção e queda de folhas e de frutos (A $x \mathrm{~B})$, tonalidade de folhas na região de crescimento $(\mathrm{C} x \mathrm{D}) \mathrm{e}$ retenção e queda do tufo terminal (E $x$ F). Fotos: Luiz Gonzaga Biones Ferraz.
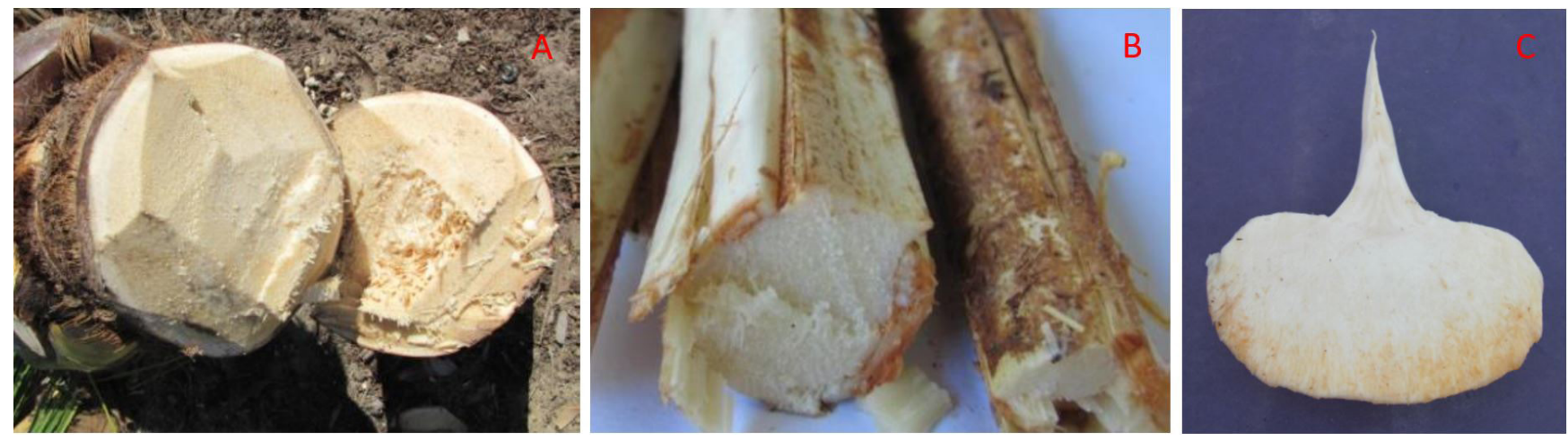

Figura 9. Visão interna do estipe de coqueiro com sintomas da ALCC. Base do estipe (A); região de ligação estipe-coroa (B); e gema apical (C). Fotos: Luiz Gonzaga Biones Ferraz. 
Foi isolado Fusarium sp., também, de tecidos de cocos jovens que apresentavam sinais de doença (Figura 10). As amostras foram oriundas do coqueiral consorciado com bananeira e de outros em plantio solteiro, na mesma propriedade e em outra região de cultivo.

\section{Etiologia}

O patossistema da ALCC continua indefinido. Os resultados de inoculação com Fusarium sp. em tecidos foliares e em cocos jovens não acusaram patogenicidade.

\section{Diversidade genética em Fusarium}

Constatou-se ampla variação na tonalidade de isolados de Fusarium sp. de tecidos foliares de coqueiro som sintomas da ALCC. Segundo Lazarotto (2013), diferença de tonalidade de isolados pode se constituir indicativo de variabilidade genética dentro do gênero Fusarium.

Foi realizada análise de diversidade genética por meio de marcador inter simple sequence repeat (1SSR) em DNA genômico extraído de acordo com o protocolo descrito por Murray e Thompson (1980).

Houve alta diversidade genética quanto à amplificação e distribuição de bandas polimórficas abaixo de 2.000 pb, com distribuição de isolados de Fusarium sp. em, pelo menos, três grupos (Figura 11).

\section{Análise molecuar em Fusarium}

O fungo foi submetido à análise morfológica (LESLIE; SUMMERELL, 2006) e molecular; nesse caso pelos genes Tef1 (O’DONNELL et al., 2008) e Rpb2 (LIU et al., 1999).

O DNA de um isolado de fragmentos de tecidos foliares foi identificado como Fusarium sacchari (E.J. Butler) W. Gams, complexo Fujikuroi.

Apesar desse fungo não ser patogênico para coqueiro, o resultado despertou curiosidade por ele não ter sido identificado no filoplano do coqueiro em Pernambuco (LIRA, 1990). Outro fungo que também não foi identificado por esse autor foi o Ceratocystis paradoxa, agente da doença 'resinose', antes citada e que atualmente é problema no Brasil.
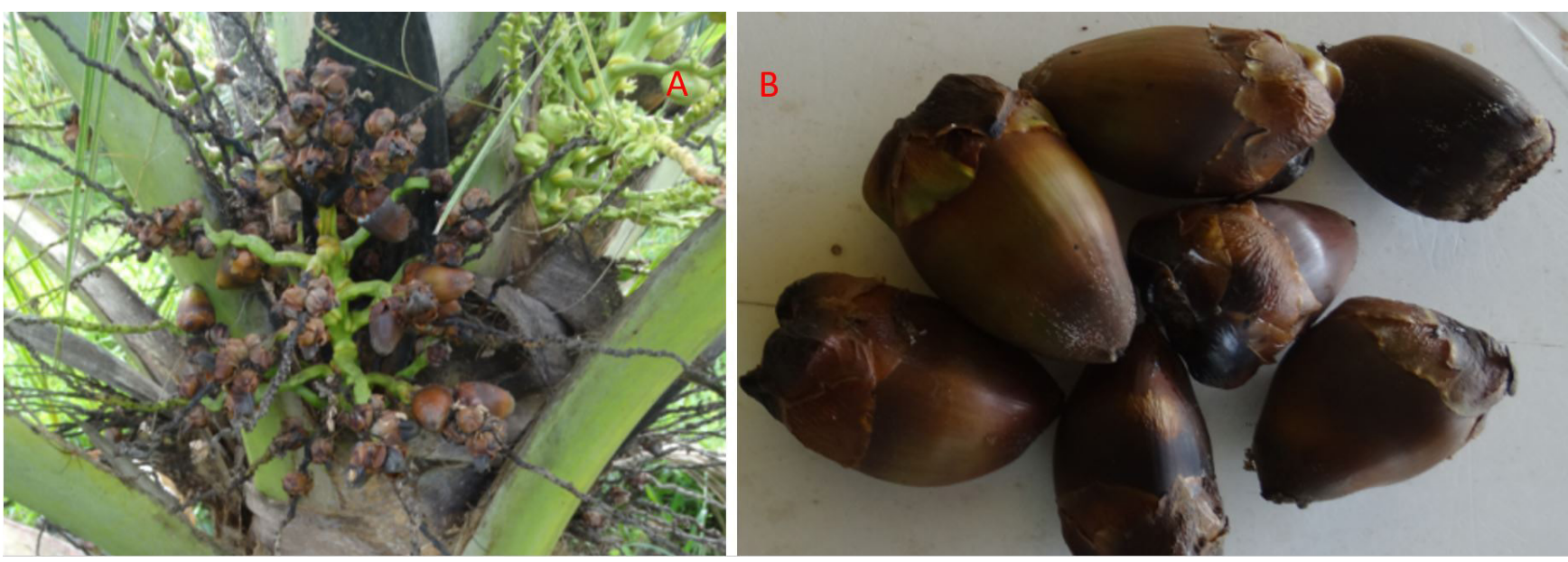

Figura 10. Coqueiros com frutos jovens com sinais de doença (A) e amostras dos mesmos (B) de cujos tecidos foi isolado Fusarium sp. Sítio Pedra Pintada, localidade Brejinho, Alto Bonito, Bonito, Pernambuco, Brasil. Fotos: Luiz Gonzaga Biones Ferraz.
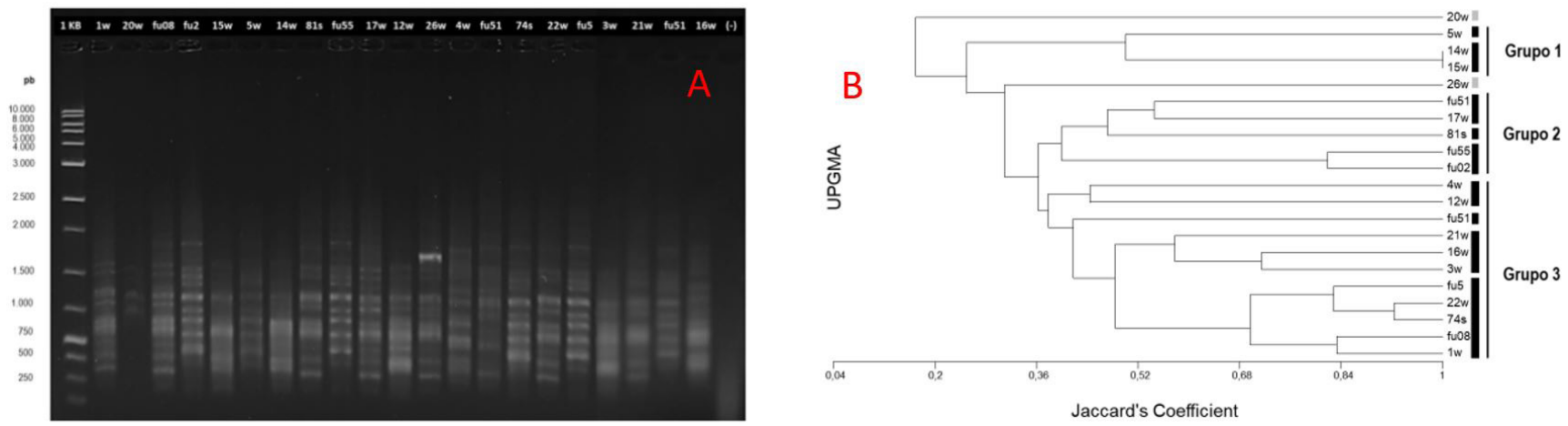

Figura 11. Padrão de amplificação de DNA (A) de isolados de Fusarium sp., com marcador ISSR (GTG), e dendograma (B) resultante do agrupamento UPGMA a partir de dados de similaridade genética entre bandas polimórficas de isolados de Fusarium sp. com sintomas da ALCC, comparadas pelo coeficiente de Jaccard. Foto: Iwanne Lima Coelho. 


\section{Considerações}

No início da ocorrência da ALCC foi ventilada a possibilidade de a redução de tecidos de coqueiro estar associada à deficiência de boro. Essa hipótese foi descartada a partir de resultados de análise foliar, dando lugar à provável participação da deficiência de zinco (FERRAZ et al., 2012b).

A redução acentuada de tecidos vegetais e reprodutivos dos vegetais em geral pode estar associada à deficiência desse elemento. Além de cofator em diversas reações enzimáticas, o zinco é requerido na síntese do aminoácido Triptofano, que é precursor do Ácido Indolacético (AIA), hormônio de crescimento (MENGEL; KIRKBY, 1982).

É possível que a deficiência de zinco possa ter contribuído para o oportunismo de Fusarium sp. Segundo BorgesPérez et al. (1991), a aplicação de zinco provocou redução no número de bananeiras (Dwarf Cavendish) atacadas pela doença mal-do-Panamá, causada por Fusarium oxysporum f. sp. cubense. Esses autores consideram a possibilidade de o zinco ter auxiliado na formação de tilose, que faz parte do sistema de defesa da planta.

A boa resposta à aplicação de defensivos agrícolas em coqueiral comercial pode estar associada, também, à participação desse micronutriente ou de alguns outros na composição de produtos comerciais usados.

É nítida a semelhança que há entre sintomas da ALCC e de plantas localizadas na Guiana e no Caribe. Esse último registro é por demais preocupante, considerando o que a 'porroca' tem provocado ali, podendo se estender para outras regiões nucícolas.

\section{Conclusão}

- ALCC poderá se constituir grave ameaça aos coqueirais brasileiros;

- Urge que se unam esforços para definição da etiologia da ALCC;

- Há necessidade de levantamento nacional visando à ocorrência da ALCC;

- Deve ser investigada a relação ALCC versus disponibilidade de zinco;

- Merece ser discutida a adoção de micronutrientes no sistema de produção de coco, contemplando: elemento, momento e forma de aplicação, dose e formulação;

- Há de se investigar causas para a presença de Fusarium sp. em folhas e frutos;

- É fundamental a detecção da doença nos seus estágios iniciais;

- Há indicativo para estudo molecular em Fusarium associado à ALCC;

- Deve ser avaliada a necessidade de medidas preventivas na fronteira com a Guiana;

- Seria salutar a participação do MAPA e de coirmãs estaduais em discussões futuras;
- O levantamento da micoflora do filoplano do coqueiro necessita ser atualizado.

\section{Agradecimentos}

Agenor Torres, Ângela Vilela, Antonio Alves, Beraldo Cavalcante, Clístenes Williams, Maria Conceição, Dão, Domingos Eduardo, Edwardo Ferreira, Evandro Luiz, Fhelipe Viana Quaglia, Genira Andrade, Gilvan Pio, Joana Ferreira, João Alberto Santos, João Moura, José Carlos Barbosa, Edilson Mesquita, José Jorge Tavares, Luiz Cláudio Estrela, Mário Barbosa, Michel Dollet, Pedro Justino, Pedro Martins, Regina Ceres, Rido Sartori (em memória), Rodrigo Coitinho, Rosalvo Rocha, Tiago Barbosa, Vanildo Cavalcanti, Venézio Felipe e Zeilton Ferraz.

\section{Referências}

BORGES-PÉREZ, et al. Enhanced resistance of banana plants (Dwarf cavendish) to Fusarium oxysporum f. sp. cubense by controlled Zn nutrition under field conditions. Banana Newsletter, San Salvador, n. 14, p. 24-26, 1991.

BOURDEIX, R. et al. Yellowing diseases of the coconut palm: an overview. 2016. Disponível em: $<$ http://plantapalm.com/vpe/ pestsndiseases/vpe_ly_coconut.htm $>$. Acesso em: 30 out. 2016.

DINIZ, F. Ácaro vermelho das palmeiras foi encontrado pela primeira vez no Brasil. Brasília: Embrapa, 2009. Disponível em: $<$ https:// www.embrapa.br/web/portal/busca-de-noticias/-/noticia/18052528/ acaro-vermelho-das-palmeiras-foi-encontrado-pela-primeira-vezno-brasil>. Acesso em: 7 jun. 2017.

FERRAZ, L. G. B. et al. Resinose em coqueiro na faixa litorânea de Pernambuco. Tropical Plant Pathology, Brasília, v. 38, p. 584, 2012a. Suplemento.

FERRAZ, L. G. B. et al. Nova doença letal ao coqueiro no Brasil. Tropical Plant Pathology, Brasília, v. 38, p. 583, 2012b. Suplemento.

FERREIRA, J. M. S. et al. A cultura do coqueiro no Brasil. 2. ed. Brasília: Embrapa-SPI; Aracaju: Embrapa-CPATC, 1998. p. 189-267.

HARRISON, N. A.; ELLIOTT, M. L. Lethal yellowing of palm. St. Paul: American Phytopathological Society, 2008. Disponível em: $<$ https://www.apsnet.org/edcenter/intropp/lessons/prokaryotes/ Pages/LethalYellowing.aspx> . Acesso em: 2 out. 2018.

INSTITUTO BRASILEIRO DE GEOGRAFIA E ESTATÍSTICA - IBGE Produção agrícola municipal: culturas temporárias e permanentes. Rio de Janeiro, 2015. Disponível em: <http://biblioteca.ibge.gov. br/visualizacao/periodicos/66/pam_2015_v42_br.pdf >. Acesso em: 4 jun. 2017.

LAZAROTTO, M. Identificação e caracterização de Fusarium spp. e Pestalotiopsis spp associados a Carya illinoinensis no Rio Grande do Sul. 2013. 156 f. Tese (Doutorado em Engenharia Florestal)-Universidade Federal de Santa Maria, Santa Maria, 2013. Disponível em: <https://www.agricultura.rs.gov.br/upload/ arquivos/201711/07100433-fusarium-spp-e-pestalotiopsis-spp-tesemarilia-lazarotto.pdf>. Acesso em: 6 ago. 2019.

LESLIE, J. F.; SUMMERELL, B. A. The fusarium laboratory manual. Iowa: Editora Blackwell Publishing, 2006. 388 p. 
LIRA, R. V. F. Levantamento da micoflora do filoplano do coqueiro (Cocos nucifera L.) em diferentes áreas do Nordeste do Brasil. 1990. 170 f. Dissertação (Mestrado)-Universidade Federal Rural de Pernambuco, Recife, 1990.

LIU, Y. J. et al. Phylogenetic relationships among ascomycetes: evidence from an RNA polymerse II subunit. Molecular Biology and Evolution, Chicago, v. 16, p. 1799-1808, 1999.

MENGEL, K.; KIRKBY, E. A. Principles of plant nutrition. 3rd ed. Bern: International Potash Institute, 1982. 655 p.

MURRAY, M. A. S.; THOMPSON, W. F. Rapid isolation of high molecular weight plant DNA. Nucleic Acids Research, Oxford, v. 8, n. 19, p. 4321-4326, 1980.

O'DONNELL, K. et al. Molecular phylogenetic diversity, multilocus haplotype nomenclature, and in vitro antifungal resistance within the
Fusarium solani species complex. Journal Clinical Microbiology, Washington, v. 46, n. 8, p. 2477-2490, 2008.

SILVA, P.M. Coqueiral: dossiê, vida e agonia. Recife: [s.n.], 2016. Mimeografado.

UNIVERSITY OF CALIFORNIA. Novel host-pathogen interactions. Santa Cruz, 2019. Disponível em: <http://parker.eeb.ucsc.edu/ research/evolutionary-ecology-of-plant-disease/>. Acesso em: 3 out. 2019

VILLAREAL, J. B. Porroca, enemigo silencioso y letal. Panamá: IDIAP, 2019. Disponível em: <http://www.idiap.gob.pa/2015/11/20/ porroca-enemigo-silencioso-y-letal/> . Acesso em 3 out. 2019.

Recebido: 23 mar. 2020 Aprovado: 04 ago. 2020 